\title{
Kern Singh: Spine essentials handbook: a bulleted review of anatomy, evaluation, imaging, tests, and procedures
}

\author{
Thieme Publishers, New York, Stuttgart, 2019, (ISBN 9781626235076)
}

\author{
Parmenion P. Tsitsopoulos ${ }^{1}$
}

Received: 17 July 2019 / Accepted: 18 July 2019 / Published online: 26 July 2019

(C) Springer-Verlag GmbH Austria, part of Springer Nature 2019

The Spine Essentials Handbook is a recently published portable source by Dr. Kern Singh and numerous contributors. This handbook covers the fundamentals of spine knowledge and practice through a practical and an in-depth approach by the authors. As such, a comprehensive review on spine anatomy, physiology, pathologies, clinical and radiological evaluation, management strategies, and complications from the craniovertebral junction to the sacrococcygeal region is undertaken.

he first seven chapters are addressing the major aspects of spine anatomy and physiology. After an initial presentation of general neuroanatomical and physiological characteristics, each spine segment is scrutinized both from the musculoskeletal and neuronal perspective. Although a thorough presentation is done which is accompanied by nice illustrations and informative tables, someone should expect this part to be less analytical since it covers more than one third of the book's total length. The next two chapters are dealing with core knowledge on clinical examination and radiological principles, both presented in a comprehensive way with no redundant information.

In the following seven chapters, the authors explore the main pathologies seen in spine practice. Specifically, cervical and lumbar disc disease, deformities, spine trauma, tumors, infections, and pediatric problems are reviewed separately in a fine way. Of note, in the chapter of spine trauma, the recent useful AOSpine classification is missing. The next seven chapters are dedicated to surgical strategies and techniques. This part is well constructed since each chapter is subdivided into indications, patient positioning, surgical approach, use of hardware, and complications. These chapters are also enriched by representative cases from

Parmenion P. Tsitsopoulos

ptsitsopoulos@auth.gr

1 Department of Neurosurgery, Hippokatio General Hospital, Aristotle University of Thessaloniki, Thessaloniki, Greece everyday spine practice which are very helpful for the reader and for spine clinicians in general. The book concludes with the presentation of major surgical and medical complications that are encountered in spine practice.

This handbook includes numerous high-quality schematic drawings, classic and modern radiological images, and detailed tables while few topics are also enriched with helpful algorithms. Although the wide coverage of spine knowledge by the contributors is acknowledged, the neurosurgical element is, at some parts, missing or incompletely addressed. In particular, chapters on intradural pathologies such as intradural extramedullary tumors, intramedullary tumors, and tethered cord are not included. This is a downside which the authors should take into account if they plan to update the content in the future.

The current textbook is an interesting endeavor to collect, present, and analyze the existing knowledge on spine practice by means of a comprehensive overview. The fact that medical students and residents have also contributed to the final result is impressive. Overall, the Spine Essentials Handbook by Kern Singh and collaborators can become an important source and reference point for medical students, residents, specialized neurosurgeons, and orthopedic surgeons, as well as for other spine practitioners such as physiatrists and chiropractors.

Publisher's note Springer Nature remains neutral with regard to jurisdictional claims in published maps and institutional affiliations. 